\title{
Risk factors associated with acute coronary syndrome in northern saudi arabia
}

\begin{abstract}
Objective: The aim of this study was to find out the common risk factors associated with Acute Coronary Syndrome (ACS) in Northern Kingdom of Saudi Arabia (KSA).

Methodology: One hundred and fifty six patients with ACS were investigated in intensive care unit (ICU), at cardiac center in King Khalid Hospital, in northern KSA, city of Hail.

Results: Risk factors for ACS including; Hypertension, Ischemic Heart Disease (IHD), Smoking, Diabetes Miletus (DM), and Dyslipidemia were found in $68.6 \%, 34.6 \%, 20.5 \%$, $59 \%$ and $83.3 \%$ of the patients, respectively.

Conclusion: The most common risk factors for ACS in northern KSA (Hail region) were dyslipidemia and hypertension. These favored the urgent need for intervention and control, which lower the burden of ACS.
\end{abstract}

Keywords: acute coronary syndrome, unstable angina, NSTEMI, STEMI
Volume 8 Issue 3 - 2017

\author{
Shrafeldin MAlhassan,' Hussain Gadelkarim \\ Ahmed,' Bassam Ahmed Almutlaq,' Abdullah \\ Abdulmohsen Alanqari,' Rawaby Khalid \\ Alshammari,' Khalid Turki Alshammari,' \\ Huwayt Abdualmohseen Alshammari,' \\ Joharah Issa Almubrad, ${ }^{2}$ Husain Alturkistani, ${ }^{3}$ \\ Majed Zannon Turkustani, ${ }^{4}$ Abdulmalik \\ Hassan Alsabban ${ }^{4}$ \\ 'College of Medicine, University of Hail, Kingdom of Saudi \\ Arabia \\ ${ }^{2}$ College of Medicine, King Saud University, Kingdom of Saudi \\ Arabia \\ ${ }^{3}$ Department of Radiology and Medical Imaging, College of \\ Medicine, King Saud University, Kingdom of Saudi Arabia \\ ${ }^{4}$ Bateriy Medical College, Kingdom of Saudi Arabia
}

Correspondence: Hussain Gadelkarim Ahmed, College of Medicine, University of Hail, Kingdom of Saudi Arabia, Email hussaingad1972@yahoo.com

Received: February 06, 2017| Published: February 27, 2017

\section{Introduction}

ACS is a group of clinical symptoms well-matched with acute myocardial ischemia, representing the most important cause of death worldwide, with a great clinical and financial impact. The clinical types of ACS includes unstable angina and acute myocardial infarction (AMI) with or without ST-segment elevation. ${ }^{1}$

The mechanism of ACS includes a complicated interaction among the endothelium, the inflammatory cells, and the thrombogenicity of the blood. ${ }^{2,3}$ Angiographically, non-critical coronary lesions $(<50 \%$ stenosis in the diameter of the vessel) may be accompanied with abrupt progression to severe or complete occlusion and may ultimately account for two-thirds of cases of ACS., ${ }^{4,5}$ Factors such as, the severity of the plaque rupture, the lipid and tissue factor content of the plaque, the degree of inflammatory reactions at the site, and the blood flow in the area, are important in monitoring the amount of thrombus formation which defining whether a given plaque rupture will cause ACS. ${ }^{6-8}$ Previous studies using intravascular ultrasonography have revealed that at least $80 \%$ of patients with ACS display multiple plaque ruptures distinct from the culprit lesion. ${ }^{9}$

There are many modifiable risk factors for ACS. Most risk factors that initiate cardiovascular disease have genetic, physiologic, behavioral, and environmental components. Non-modifiable risk factors include age, genetics, and gender. Modifiable risk factors comprise smoking, dyslipidemia, hypertension, and diabetes, with obesity and metabolic syndrome are commonly involved. ${ }^{10-12}$ The Saudi Project for assessment of coronary events recruited patients admitted with ACS from 17 hospitals in KSA from 2005 to 2007. A total of 4523 patients with ACS were investigated, of whom 905 $(20 \%)$ had Congestive Heart Failure (CHF).${ }^{13}$ With a lack of studies from KSA regarding ACS, Saudi population has diverse racial, socioeconomic, and demographic characteristics which might be risk factors for ACS in different KAS regions. Therefore, the aim of the present study was to assess risk factors associated with Acute Coronary Syndrome in Northern Saudi Arabia.

\section{Materials and methods}

This is a retrospective descriptive study conducted in coronary care unit (CCU) at King Khalid Hospital-cardiac Centre, Hail, KSA. One thousand and nine hundred patients were referred to cardiac Centre during one year time, with suspected cardiac diseases. One hundred and fifty six patients were categorized as having acute coronary syndrome (ACS) and were further included as study subjects (cases). Records regarding patients with ACS were retrieved from patient's files in CCU. The diagnosis of ACS was based on physical examination, electrocardiography, radiologic tests, cardiac biomarker estimations and patient's history. On diagnosis ACS, ACS was further categorized into unstable angina (UA), none-ST-segment elevation myocardial infarction (NSTEMI), and ST-segment elevation myocardial infarction (STEMI). Data regarding the underlying risk factors such as a positive family history, diabetes mellitus, smoking, hypertension, dyslipidemia and demographical characteristics, complications and outcome were also revised.

\section{Statistical analysis}

Data management was done using Statistical Package for Social Sciences (SPSS version 16). SPSS was used for analysis and to perform Pearson Chi-square test for statistical significant (P value $\mathrm{P}<0.5)$. The $95 \%$ confidence level and confidence intervals were used.

\section{Ethical consent}

The protocol of the present study was approved by the ethical 
committee at College of Medicine, University of Hail. The informed consent was agreed about by Pulmonary Medicine Department at King Khalid Hospital. All procedures performed this study were in accordance with the ethical standards of the 1964 Helsinki declaration and its later amendments or comparable ethical standards.

\section{Results}

The current study investigated 156 patients with ACS, their age ranging from 27 to 90 years with a mean age of 59years old. Of the 156 patients, $130 / 156(83.3 \%)$ were males and $26 / 156(16.7 \%)$ were females, giving males' females' ratio of 5.00:1.00. Most of the patients (both males and females) were diagnosed with STEMI followed by NSTEMI and UA, representing 83/156(53.2\%), $43 / 156(27.6 \%), 30 / 156(19.2 \%)$, in this order. The males and females constituted $69 / 83(83 \%)$ \& $14 / 83(17 \%), 38 / 43(88.4 \%) \&$ $5 / 43(11.6 \%)$ and $25 / 30(83.3 \%) \& 5 / 30(16.7 \%)$ of STEMI, NSTEMI and $\mathrm{AU}$, respectively. Saudi civilian represent the majority of cases $137 / 156(87.8 \%)$. Of the 137 Saudi patients 74/137(54\%), $39 / 137(28.5 \%)$ and $24 / 137(17.5 \%)$, were found with STEMI, NSTEMI and UA, respectively. Non-Saudi patients represented 19/156(12.2\%). Among non-Saudi patients, most of the patients were detected with STEMI constituting 9/19(47.4\%) followed by UA and NSTEMI, representing 6/19(31.6\%) and 4/19(21\%), respectively, as indicated in Table 1 and Figure 1.

Table I Distribution of ACS by Demographical characteristics

\begin{tabular}{llllll}
\hline Variable & Category & UA & NSTEMI & STEMI & Total \\
\hline Sex & Males & 23 & 38 & 69 & 130 \\
& Females & 7 & 5 & 14 & 26 \\
\multirow{4}{*}{ Nationality } & Total & 30 & 43 & 83 & 156 \\
& Saudi & 24 & 39 & 74 & 137 \\
Age & Non-Saudi & 6 & 4 & 9 & 19 \\
& $<45$ years & 3 & 8 & 18 & 29 \\
& $46-55$ & 11 & 9 & 14 & 34 \\
& $56-65$ & 8 & 13 & 27 & 48 \\
& $66-75$ & 4 & 11 & 14 & 29 \\
& $76+$ & 4 & 2 & 10 & 16
\end{tabular}

Table 2 Distribution of ACS by Hypertension, IHD and Smoking

\begin{tabular}{lllllll}
\hline Variable & Category & UA & NSTEMI & STEMI & Total & P value \\
\hline Hypertension & Yes & 26 & 28 & 53 & 107 & 0.00 I \\
& No & 4 & 15 & 30 & 49 & 156 \\
IHD & Total & 30 & 43 & 83 & 54 & 102 \\
\multirow{2}{*}{ Smoking } & Yes & 19 & 19 & 16 & 32 & 124 \\
& No & 11 & 24 & 67 & 16 &
\end{tabular}

Table 3 Distribution of ACS by Family history of IHD, DM and Dyslipidemia

\begin{tabular}{llllll}
\hline Variable & Category & UA & NSTEMI & STEMI & Total \\
\hline Family History (IHD) & Yes & 0 & 5 & 5 & 10 \\
& No & 30 & 38 & 78 & 146 \\
& Total & 30 & 43 & 83 & 156 \\
DM & Yes & 18 & 27 & 47 & 92 \\
\multirow{3}{*}{ Dyslipidemia } & No & 12 & 16 & 36 & 64 \\
& Yes & 22 & 37 & 71 & 130 \\
& No & 8 & 6 & 12 & 26 \\
\hline
\end{tabular}




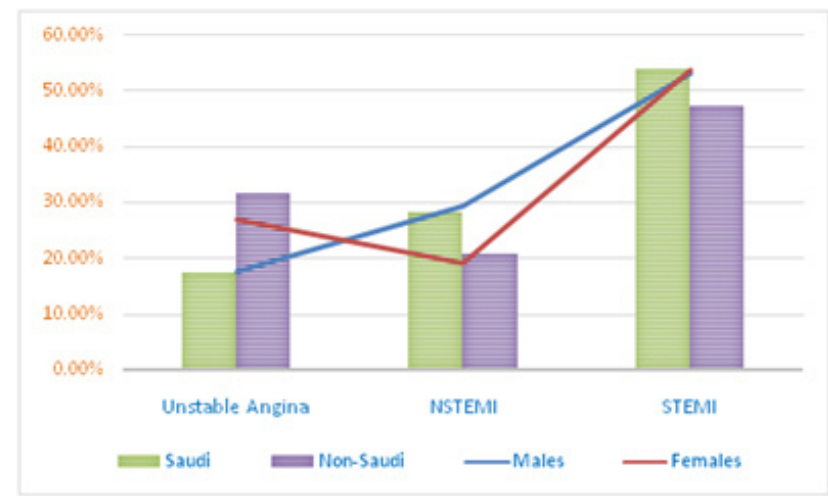

Figure I Description of the ACS by Sex and Nationality.

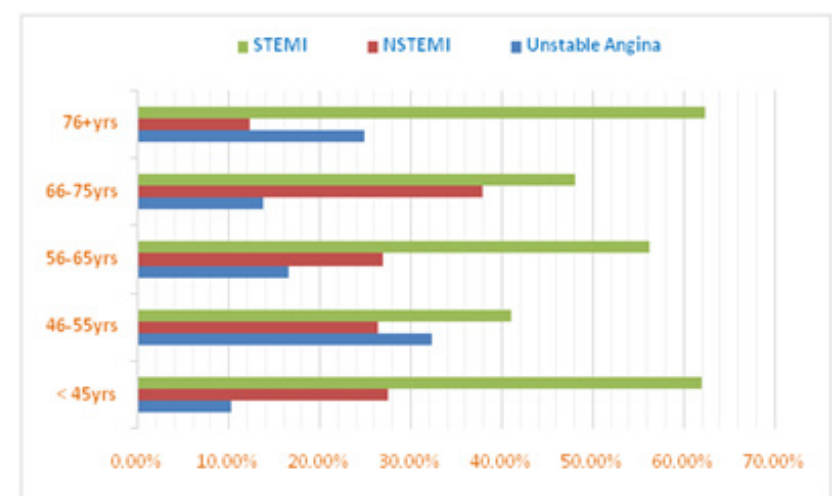

Figure 2 Description of the ACS by age.

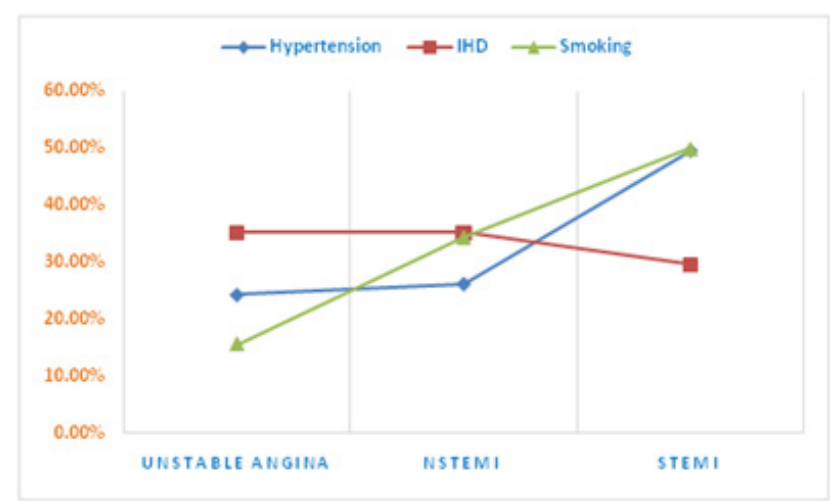

Figure 3 Description of the ACS by Hypertension, IHD and Smoking.

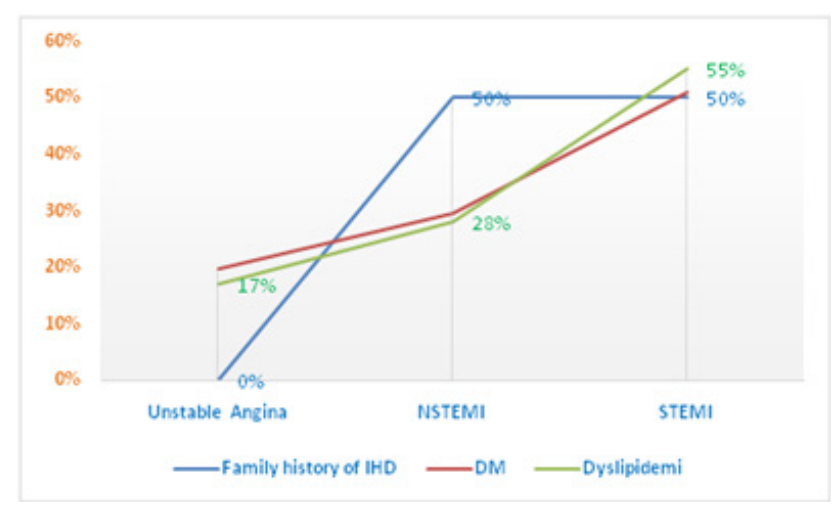

Figure 4 Description of the ACS by Family history of IHD, DM and Dyslipidemia.

\section{Discussion}

In the present study we found high proportions of different risk factors that associated with various categories of ACS. The most common factors were sex, age hypertension, IHD, smoking, DM, and dyslipidemia. In the current study dyslipidemia scored $83.3 \%$ of the patients with ACS and this was the highest percentage among these risk factors. The great majority of patients with ACS in the current study were elderly males. Such relationship (the occurrence of ACS in elderly men) were well established in several studies. ${ }^{14}$ In the present study, most of the males were found with STEMI, followed by NSTEMI and unstable angina respectively. On the other hand, most of the females were observed with STEMI but followed by UA. Compared to men, women with high-risk for ACS undergo less coronary angiography, and angioplasty. Further more women do not have higher incidence of cardiovascular death, recurrent MI, or stroke, thus, they undergo a higher rate of refractory ischemia and re-hospitalization. ${ }^{15}$ It was documented that about $33 \%$ of all ACS episodes happen in patients over $75 y$ years old and account for approximately $60 \%$ of total mortality due to ACS. ${ }^{16-18}$ The incidence of ACS in the elderly is expected to rise due to improvements in prior ACS treatment in an aging population. ${ }^{18}$

However, the presentation of dyslipidemia among patients with ACS, differ in different studies, which may indicate some sort of demographical factors influence. Moreover, the majority of cases of dyslipidemia were found with STEMI followed by NSTEMI. May studies have shown that dyslipidemia is one the major risk factors which is extensively prevalent in patients with ACS and is more predominant in males than in females ${ }^{20}$. In a study investigated the rate of incidence, clinical and angiographic characteristics, and longterm clinical outcome of ACS in Swiss hospitals. Current smoking (81\%) and dyslipidemia (59\%) were the most common risk factors. ${ }^{21,22}$

Hypertension $(68.6 \%)$ was one of the prominent risk factors in the present study. Notably, the great majority of patients with hypertension were found with STEMI followed by NSTEMI. In general, the prevalence of hypertension rises progressively with age in both men and women and ac as strong risk factor for $\mathrm{ACS} .{ }^{23} \mathrm{~A}$ previous study revealed a $63.4 \%$ prevalence of hypertension among ACS patients. ${ }^{24}$ However, in patients with acute myocardial infarction (AMI), the prevalence of hypertension varies from 31 to $59 \% .{ }^{25} \mathrm{~A}$ recent study from Barazil has reported that the main risk factors were arterial hypertension (68\%), smoking (67\%), and dyslipidemia (43\%). ${ }^{26}$

Our study revealed a 59\% prevalence of DM among ACS patients. $\mathrm{DM}$ is a major independent risk factor for acute coronary syndrome (ACS). Diabetic patients with ACS suffer from higher mortality compared to their nondiabetic peers. ${ }^{27}$ The presence of type 2 DM extends the risks associated with ACS, increasing the risk of recurrent cardiovascular events (CVEs) and doubling the risk of death. Managing cardiovascular risk factors has slight outcome on lowering the mortality risk in patients with type $2 \mathrm{DM} \cdot{ }^{28}$ According to proof obtained from large epidemiological studies, an incidence rate of ACS in diabetics is 2-3times higher than in general population. ${ }^{29}$

Our study revealed a 59\% prevalence of history of IHD among ACS patients. At definite time periods following ischemic stroke (IS), ACS as IHD represents a higher risk of death than IS. Not all IS patients can undergo specific examination for IHD detection. IS patients are mostly endangered by stroke recurrence in the first 2 years after the onset of IS. ${ }^{30}$ After this period, coronary death due to IHD, is the leading cause of the long-term mortality in IS patients, with an incidence of $1.5-5.4 \%{ }^{31}$ Consequently, excessive efforts are 
dedicated to IHD identification and its proper management. ${ }^{32}$ The majorities of initial presentations of CVD are neither AMI nor IS, yet most primary prevention studies focus on these presentations. Sex has divergent associations with diverse CVDs, with consequences for risk prediction and management strategies. ${ }^{33}$

The present study has shown a $20.5 \%$ prevalence of DM among ACS patients. Smokers were more commonly diagnosed with STsegment elevation MI (46.0\%) than former smokers $(27.4 \%)$ and non-smokers $(30.2 \%) \quad(\mathrm{P}<0.001)$. Smokers were habitually men, were younger and more aggressively treated than ex-smokers and non-smokers through the three acute coronary syndrome groups. ${ }^{34}$ Family history of IHD was identified in $6.4 \%$ of the patients ACS. Although, there is a debate about the role of positive family history as an independent risk factor for coronary artery disease, it was reported that, positive family history is a major risk factor for coronary artery disease which intensely predisposes to the atherosclerotic development at younger ages; therefore, these patients should be assessed and managed more intensively for other risk factors. ${ }^{35}$ Family history of coronary heart disease (CHD) is a well-established risk factor for CHD. Nevertheless, the prognostic association of family history has not been proven evidently in patients with AMI. ${ }^{36}$

\section{Conclusion}

There is substantial association of conventional CV risk factors, such as, dyslipidemia, hypertension, diabetes and smoking with ACS, and the high prevalence of these risk factors, mainly in relatively younger individuals, demands rapid consideration, and implementation of prevention programs to reduce the burden of CV morbidity and mortality in Northern Saudi Arabia, Hail Region.

\section{Acknowledgments}

None.

\section{Conflicts of interest}

Author declares there is no conflicts opf interest.

\section{Funding}

None.

\section{References}

1. Teich V, Piha T, Fahham L, et al. Acute Coronary Syndrome Treatment Costs from the Perspective of the Supplementary Health System. Arq Bras Cardiol. 2015;105(4):339-344.

2. Naghavi M, Libby P, Falk E, et al. From vulnerable plaque to vulnerable patient: a call for new definitions and risk assessment strategies: part I. Circulation. 2003;108(14):1664-1672.

3. Naghavi M, Libby P, Falk E, et al. From vulnerable plaque to vulnerable patient: a call for new definitions and risk assessment strategies: part II. Circulation. 2003;108(15):1772-1778.

4. Lüscher TF, Tanner FC, Noll G. Lipids and endothelial function: effects of lipid-lowering and other therapeutic interventions. Curr Opin Lipidol. 1996;7(4):234-240.

5. Chen L, Chester MR, Crook R, et al. Differential progression of complex culprit stenoses in patients with stable and unstable angina pectoris. $J$ Am Coll Cardiol . 1996;28(3):597-603.

6. Moreno PR, Bernardi VH, López-Cuéllar J, et al. Macrophages, smooth muscle cells, and tissue factor in unstable angina: implications for cellmediated thrombogenicity in acute coronary syndromes. Circulation. 1996;94(12):3090-3097.
7. Fosang AJ, Smith PJ. Human genetics: to clot or not. Nature. 2001;413(6855):475-476.

8. König A, Klauss V. Intravascular ultrasound for recognition of atherosclerotic plaques and plaque composition. Current state of the diagnostic value. Herz. 2011;36(5):402-409.

9. Rioufol G, Finet G, Ginon I, et al. Multiple atherosclerotic plaque rupture in acute coronary syndrome: a three-vessel intravascular ultrasound study. Circulation. 2002;106(7):804-808.

10. Thompson A, Gao P, Orfei L, et al. Lipoprotein-associated phospholipase $\mathrm{A}(2)$ and risk of coronary disease, stroke, and mortality: collaborative analysis of 32 prospective studies. Lancet . 2010;375(9725):1536-1544.

11. Richard Kones. Primary prevention of coronary heart disease: integration of new data, evolving views, revised goals, and role of rosuvastatin in management. A comprehensive survey. Drug Des Devel Ther. 2011;5:325-380.

12. Cziraky MJ, Reddy VS, Luthra R, et al. Clinical outcomes and medication adherence in acute coronary syndrome patients with and without type 2 diabetes mellitus: a longitudinal analysis 2006-2011. J Manag Care Spec Pharm. 2015;21(6):470-477.

13. Albackr HB, Alhabib KF, Ullah A, , et al. Prevalence and prognosis of congestive heart failure in Saudi patients admitted with acute coronary syndrome (from SPACE registry). Coron Artery Dis. 2013;24(7):596-601.

14. Bentley-Lewis R, Aguilar D, Riddle MC, et al. Rationale, design, and baseline characteristics in Evaluation of LIXisenatide in Acute Coronary Syndrome, a long-term cardiovascular end point trial of lixisenatide versus placebo. Am Heart J . 2015;169(5):631-638.e7.

15. Anand SS, Xie CC, Mehta S, et al. Differences in the management and prognosis of women and men who suffer from acute coronary syndromes. J Am Coll Cardiol. 2005;46(10):1845-1851.

16. Goldberg RJ, McCormick D, Gurwitz JH, et al. Age-related trends in short- and long-term survival after acute myocardial infarction: a 20-year population-based perspective (1975-1995). Am J Cardiol . 1998;82(11):1311-1317.

17. Roger VL, Jacobsen SJ, Weston SA, et al. Trends in the incidence and survival of patients with hospitalized myocardial infarction, Olmsted County, Minnesota, 1979 to 1994. Ann Intern Med. 2002;136(5):341-348.

18. Alexander KP, Roe MT, Chen AY, et al. CRUSADE Investigators. Evolution in cardiovascular care for elderly patients with nonST-segment elevation acute coronary syndromes: results from the CRUSADE National Quality Improvement Initiative. J Am Coll Cardiol. 2005;46(8):1479-1487.

19. CDC Public health and aging: trends in aging: United States and worldwide. MMWR. 2003;52(6):101-106.

20. Mohamed Fawzy, Addulla Abdelaziz. Prevalence and Pattern of Dyslipidemia in Acute Coronary Syndrome Patients Admitted to Medical Intensive Care Unit in Zagazig University Hospital, Egypt. World Journal of Medical Research. 2014;20(3).

21. Yusuf S, Hawken S, Ounpuu S, et al. Effect of potentially modifiable risk factors associated with MI in 52 countries (the INTERHEART study): case-control study. Lancet . 2004;364(9438): 937-952.

22. Puricel S, Lehner C, Oberhänsli $\mathrm{M}$, et al. Acute coronary syndrome in patients younger than 30 years--aetiologies, baseline characteristics and long-term clinical outcome. Swiss Med Wkly. 2013;143:w13816.

23. Picariello $\mathrm{C}$, Lazzeri $\mathrm{C}$, Attanà $\mathrm{P}$, et al. The Impact of Hypertension on Patients with Acute Coronary Syndromes. Int $J$ Hypertens. 2011;2011:563657. 
24. Maria Dorobantu, Oana-Florentina Tautu, Ana Fruntelata, et al Hypertension and acute coronary syndromes in Romania: data from the ISACS-TC registry. European Heart Journal Supplements. 2014;16(Suppl A):A20-A27.

25. Willich SN, Müller-Nordhorn J, Kulig M, et al. PIN Study Group. Cardiac risk factors, medication, and recurrent clinical events after acute coronary disease; a prospective cohort study. Eur Heart J . 2001;22(4):307-313.

26. Soeiro Ade M, Fernandes FL, Soeiro MC, et al. Clinical characteristics and long-term progression of young patients with acute coronary syndrome in Brazil. Einstein (Sao Paulo). 2015; 13(3):370-375.

27. Sethi SS, Akl EG, Farkouh ME. Diabetes mellitus and acute coronary syndrome: lessons from randomized clinical trials. Curr Diab Rep. 2012;12(3):294-304.

28. Cziraky MJ, Reddy VS, Luthra R, et al. Clinical outcomes and medication adherence in acute coronary syndrome patients with and without type 2 diabetes mellitus: a longitudinal analysis 2006-2011. J Manag Care Spec Pharm. 2015;21(6):470-477.

29. Ametov AS, P'ianykh OP, Aslandziia EN. Acute coronary syndrome in patients with type 2 diabetes mellitus. Ter Arkh. 2011;83(9):66-70.

30. Kovacik M, Madarasz S, Bartko D, et al. Cievna mozgova prihoda a ischemicka choroba srdca. Cesk Slov Neurol N. 2010;73:497-502.
31. Diener HC, Cunha L, Forbes C, et al. European stroke prevention study 2, dipyridamole and acetylsalicylic acid in the secondary prevention of stroke. J Neurol Sci. 1996;143(1-2):1-13.

32. Griva M, Naplava R, Spendlikova M, et al. Potential role of selected biomarkers for predicting the presence and extent of coronary artery disease. Biomed Pap Med Fac Univ Palacky Olomouc Czech Repub. 2010;154(3):219-225.

33. George J, Rapsomaniki E, Pujades-Rodriguez M, et al. How Does Cardiovascular Disease First Present in Women and Men? Incidence of 12 Cardiovascular Diseases in a Contemporary Cohort of 1,937,360 People. Circulation. 2015;132(14):1320-138.

34. Himbert D, Klutman M, Steg G, et al. Cigarette smoking and acute coronary syndromes: a multinational observational study. Int J Cardiol. 2010;100(1):109-117.

35. Hoseini K, Sadeghian S, Mahmoudian M, et al. Family history of cardiovascular disease as a risk factor for coronary artery disease in adult offspring. Monaldi Arch Chest Dis. 2008;70(2):84-87.

36. Prabhakaran D, Jeemon P. Should your family history of coronary heart disease scare you? Mt Sinai J Med. 2012;79(6):721-732. 